\title{
Determinants of calcium intake for prevention of osteoporosis among students: Application of the health belief model
}

\author{
Nasirzadeh Mostafa ${ }^{1}$, Ghaffari Mohtasham ${ }^{1 *}$, Rakhshanderou Sakineh ${ }^{1}$ and Hafezi \\ Bakhtiari Mona ${ }^{2}$ \\ ${ }^{1}$ Faculty of Health, Shahid Beheshti University of Medical Sciences, Tehran, Iran \\ ${ }^{2}$ Center of Health, Isfahan University of Medical Sciences, Isfahan, Iran \\ "Department of Health Education and Health Promotion, Faculty of Health, Shahid Beheshti University of \\ Medical Sciences, Tabnak Ave., Daneshjou Blvd., Velenjak, Tehran, Iran P.O. Box 19835-35511
}

\begin{abstract}
Osteoporosis reduces quality and bone density and increases fracture risk increasingly. The most important protective factors for osteoporosis are dairy products and calcium supplements. This study assesses the determinants of calcium intake in prevention of osteoporosis among students, based on health belief model. Students of Shahid Beheshti University of Medical Sciences participated in this descriptive-analytical study. The total number of participants in this study was 239 students who were studied with informed and voluntary consent. Instrument for data collection, was a valid and reliable questionnaire (including 9 demographic characteristics questions, 24 questions in health belief model constructs and standardized questionnaire FFQ. Data were analyzed SPSS version 18 Pearson correlation, t-test, ANOVA and multiple regression analysis. Mean degree of calcium intake was $945.63 \pm 629.19 \mathrm{mg} / \mathrm{day}$. Between mean degree of calcium intake and susceptibility and perceived susceptibility to osteoporosis and perceived barriers of calcium intake and education level of mother there was a significant relationship $(\mathrm{P}<0.05)$. In this study there was no significant relationship between calcium intake and other constructs of HBM $(\mathrm{P}>0.05)$. According to multiple regression analysis, perceived barriers was the strongest predictor for calcium intake (beta $=-0.14, \mathrm{P}<0.05$ ). According to the results it is recommended that future studies be conducted with a holistic view to identify determinants associated with calcium intake. Also educational interventions should be designed and implemented to change students attitude towards osteoporosis and resolve calcium intake barriers.
\end{abstract}

KEY WORDS: CALCIUM INTAKE, OSTEOPOROSIS, HBM

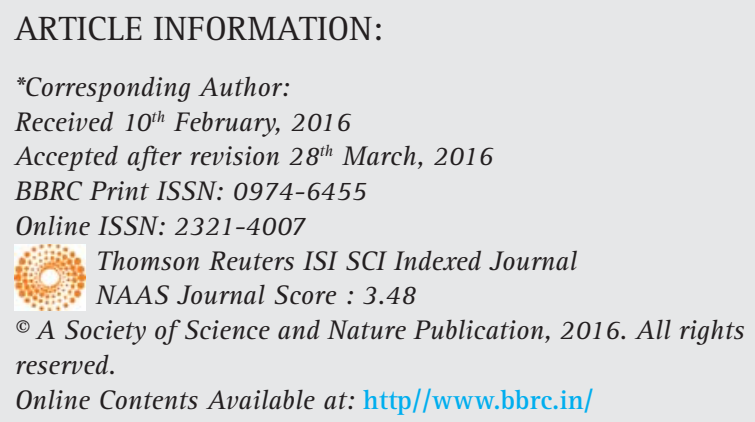




\section{INTRODUCTION}

Osteoporosis is a disease characterized by low bone mass and deterioration of bone tissue which has hit millions of people globally.This leads to increased bone fragility and risk of fracture (broken bones), particularly of the hip, spine, wrist and shoulder. Osteoporosis is often known as "the silent thief" because bone loss occurs without symptoms. Osteoporosis is sometimes confused with osteoarthritis, because the names are similar. WHO (World Health Organization) estimate of 2010 indicated that about 22 million women and 5.5 men in Europe aged 50-84, and 52 million American men and women over 50 suffer from osteoporosis. The global figures estimate that more than 1.7 million Iranians over 50 is subject to broken bones, (Lesan et al., 2010, (IOF, 2013 and MHME, 2016).

Broken bones because of the osteoporosis wields considerable costs on the health system and would have serious implications if gone untreated. Gender (osteoporosis in women is twice that in men), menopause, bright skin (Caucasians), skeleton size, smoking, caffeine, alcohol, reduced level of oestrogen, premature menopause (before 45), lower calcium and vitamin D intake, inactivity, and family history are the most important risk factors. Among factors contributing to prevention of osteoporosis are consumption of dairy products such as such as cheese, milk, eggs, fish and poultry, honey, fruit and calcium supplements (Keramat, 2012, Ghaffari, et al., 2013, Anderson, 2014 and Bonura, 2015).

The recommended daily level of calcium for young and adult people is between 1000 and $1300 \mathrm{mg}$. and intake of sufficient calcium (500 mg/day, in daylight) in individuals with osteoporosis could help prevent broken bones. WHO has provided six general recommendations to prevent osteoporosis: Increase physical activity, reduce sodium intake, increase consumption of fruits and vegetables, keep weight in a healthy condition, avoiding smoking, and restrict alcohol consumption. Research conducted in Iranian context have often reported calcium intake below the recommended levels among university students (Khadem Haghighian, 2015, NIH, 2016, WHO, 2016).

Thus, examination of the reasons behind such lower calcium intake is necessary. A preventive measure of osteoporosis is improving the bone density through health education and promotion programs (HEP) (WHO, 2016). Health education is a learning process where public receives information to change the behaviour for better in a direction to improve health. It draws upon models to explain how a behaviour takes shape; how health education is guided; and, how health education wield influence on individual's future behaviour (Mudest \& Tamayoz, 2012).
Evidence has shown that with adoption of some change in lifestyle (for example, increased calcium intake and physical activity), it is possible to prevent osteoporosis or procrastinate it (Torshizi et al., 2009). A prevalent cause of adoption of changes in behaviour to prevent osteoporosis is a fallacy that the disease is not serious. According to Health Belief Model (HBM), individuals would change their behaviour only when they understand that the disease is really serious, since otherwise, rarely would they change their behaviour for healthy lifestyle. Health belief model is an attempt to explain why some individuals engage in behaviours to prevent the disease, but some do not.

According to the model, adoption of a healthy lifestyle hinges upon two issues: first, the perception the individual has of the danger threatening him; and second, his assessment of the barriers and benefits in healthy behaviour (Glanz et al., 2008). With this in mind, the present research seeks to identify the determinants of osteoporosis-related calcium intake among university students according to Health Belief Model, to provide insights to the nature of disease to authorities to further policy decisions.

\section{MATERIAL \& METHODS}

A cross-sectional descriptive-statistical study was conducted with female students in Department of Health, Shahid Beheshti University of Medical Sciences in the educational year of 2011-12. The number of female students in the department determined the number of questionnaires as the method of data collection. Of 400 questionnaires distributed among the sample population, a total of 239 questionnaires were answered to. The first part of the questionnaire collected demographic data; the second part included 24 questions about the health belief model constructs; and the third part included the standard Food Frequency Questionnaire (FFQ).

The first part collected data on marital status, students' and their parents' employment, parents' education, income level, and university major. Of 24 questions in the second part, each construct (perceived susceptibility, severity, benefits, and perceived barriers of calcium intake) had six questions. Responses to each question was 5-point Likert scale, and had values of 'completely agree,' to 'completely disagree.' A 'completely agree' received 5 points and a 'completely disagree' was assigned only 1 point. Total scores ranged between 6 and 30. With perceived susceptibility, benefits, and severity, higher scores indicated higher perception of the constructs. Lower scores in perceived barriers indicate higher perception of the barriers. Validity and reliability of HBM constructs was confirmed in Baheiraei et al., with Cronbach's alpha coefficient of 0.78, 0.8, 0.77, 


\begin{tabular}{|c|c|c|c|c|c|}
\hline \multirow{2}{*}{$\begin{array}{l}\text { Variable } \\
\text { University major }\end{array}$} & \multicolumn{5}{|c|}{ Demographic distribution } \\
\hline & Number (per cent) & Number (per cent) & Number (per cent) & Number (per cent) & Number (per cent) \\
\hline & General Health & $\begin{array}{l}\text { Occupational } \\
\text { Health }\end{array}$ & $\begin{array}{l}\text { Environmental } \\
\text { Health }\end{array}$ & Health Education & Epidemiology \\
\hline & $(24.3) 58$ & $(21.3) 51$ & $(50.6) 121$ & $(2.1) 5$ & $(1.7) 4$ \\
\hline \multirow{2}{*}{$\begin{array}{l}\text { Degree to be } \\
\text { awarded }\end{array}$} & BA & & MA & $\mathrm{PhD}$ & \\
\hline & (95.4)228 & & (3.8)9 & $(0.8) 2$ & \\
\hline \multirow[t]{2}{*}{ Father's education } & No education & Grade school & Middle school & $\begin{array}{l}\text { High school } \\
\text { diploma }\end{array}$ & University degree \\
\hline & $(7.5) 18$ & $(15.9) 38$ & $(18.4) 44$ & $(30.5) 73$ & $(27.6) 66$ \\
\hline \multirow[t]{2}{*}{$\begin{array}{l}\text { Mother's } \\
\text { education }\end{array}$} & No education & Grade school & Middle school & $\begin{array}{l}\text { High school } \\
\text { diploma }\end{array}$ & University degree \\
\hline & $(8.8) 21$ & $(25.1) 60$ & $(20.5) 49$ & $(32.6) 78$ & (13)31 \\
\hline \multirow[t]{2}{*}{ Father's job } & Unemployed & Blue-collar job & White-collar job & & Other \\
\hline & (3.3)8 & $(5.4) 13$ & (56.9) 136 & & $(34.4) 82$ \\
\hline \multirow[t]{2}{*}{ Mother's job } & Housewife & White-collar job & & & Other \\
\hline & $(87.9) 210$ & $(2.5) 6$ & & & $(9.6) 23$ \\
\hline \multirow[t]{2}{*}{ Family income* } & Low & Average & Good & & High \\
\hline & (5) 12 & $(25.5) 61$ & (64) 153 & & $(5.4) 13$ \\
\hline \multirow[t]{2}{*}{ Marital status } & \multicolumn{2}{|c|}{ Single } & & \multicolumn{2}{|c|}{ Married } \\
\hline & \multicolumn{2}{|c|}{$(91.6) 219$} & & \multicolumn{2}{|c|}{$(8.4) 20$} \\
\hline \multirow[t]{2}{*}{ Students' job } & \multicolumn{2}{|c|}{ Employed } & & \multicolumn{2}{|c|}{ Unemployed } \\
\hline & \multicolumn{2}{|c|}{ (7.1) 17} & & \multicolumn{2}{|c|}{ (92.9)222 } \\
\hline
\end{tabular}

and 0.7 for susceptibility, severity, benefits, and barriers, respectively (WHO, 2013). The third part included 19 question of food frequency, which measured consumption of variety of foods such as high-tat, low-tat, fatless milk, cacao mixed with milk, milk chocolate, high-fat and normal-fat yogurt, yogurt drink, traditional icecream, raw and boiled spinach, and turnips.

The responses was in 9-point Likert scale, ranging from never consumed to more than six times and more per day. Scoring to responses was based on calcium content of consumed items. For calculating calcium content, we drew upon a table giving the daily permitted amount of food in gr/day. The unit was calcium content of each $100 \mathrm{gr}$ of the given food, thus calculating the total calcium intake of the individual per day. We demanded that each student carefully study the questionnaire, and if willing, fill the questionnaires. The data collected was fed into SPSS-18 statistical software, which gave us an analysis of the data drawing upon Pearson's correlation coefficient, independent t-test, one-way analysis of variance and multivariate regression, and in the significance level of 0.05 per.

\section{RESULTS AND DISCUSSION}

A total of 239 female students filled in the questionnaire, of which 228 females (95.3 per cent) was BA students. They averaged $22.17 \pm 2.66$ (range of 18-44) in age. 219 students were married (91.6 per cent) and 20 students were singles (8.54 per cent). Male parent of 66 students (27.6 per cent) and female parent of 31 students (13 per cent) had university degrees. The female parent of 210 students (87.9 per cent) were housewives and male parent of 136 students (56.9 per cent) had white-collar jobs. Only 5.4 per cent of students gave their parents income level as quite high.

Students received a mean of $945.63 \pm 629.19 \mathrm{mg} /$ day calcium through consumption of variety of the above items. There was a significant relationship between calcium intake and perceived susceptibility, severity, and barriers $(\mathrm{P}<0.05)($ Table 2$)$. Students with female parents who had high school diploma, reported highest level of calcium intake, thus showing a significant relationship $(\mathrm{P}<0.05)$. we also did not find a significant relationship between calcium intake and perceived susceptibility, stu- 
Table 2: Correlation between calcium intake and Health Belief Model constructs.

\begin{tabular}{|c|c|c|c|c|c|c|}
\hline \multirow[b]{2}{*}{ Variable } & \multirow[b]{2}{*}{$\begin{array}{l}\text { Mean \& } \\
\text { standard } \\
\text { deviation }\end{array}$} & \multicolumn{5}{|c|}{ Pearson's correlation of coefficient } \\
\hline & & $\begin{array}{l}\text { Calcium } \\
\text { intake }\end{array}$ & $\begin{array}{l}\text { Perceived } \\
\text { susceptibility }\end{array}$ & $\begin{array}{l}\text { Perceived } \\
\text { severity }\end{array}$ & $\begin{array}{l}\text { Perceived } \\
\text { benefits }\end{array}$ & $\begin{array}{l}\text { Perceived } \\
\text { barriers }\end{array}$ \\
\hline $\begin{array}{l}\text { Daily calcium } \\
\text { intake }\end{array}$ & $945.63 \pm 629.19$ & 1 & $-0.201^{* *}$ & $-0.15^{*}$ & 0.04 & $-0.206^{* *}$ \\
\hline $\begin{array}{l}\text { Perceived } \\
\text { susceptibility }\end{array}$ & $15.19 \pm 4.45$ & $-0.201^{* * *}$ & 1 & $0.34^{* * *}$ & -0.05 & $0.31^{* * *}$ \\
\hline $\begin{array}{l}\text { Perceived } \\
\text { severity }\end{array}$ & $18.19 \pm 4.45$ & $-0.15^{*}$ & $0.34^{* * *}$ & 1 & -0.06 & $0.26^{* *}$ \\
\hline $\begin{array}{l}\text { Perceived } \\
\text { benefits }\end{array}$ & $13.79 \pm 2.72$ & 0.04 & -0.05 & -0.06 & 1 & 0.03 \\
\hline Perceived barriers & $13.49 \pm 3.96$ & $-0.206^{* * *}$ & $0.31^{* * *}$ & $0.26^{* * *}$ & 0.03 & 1 \\
\hline
\end{tabular}

\begin{tabular}{|c|c|c|c|c|c|}
\hline & \multicolumn{2}{|c|}{ Unstandardized coefficients } & \multirow[b]{2}{*}{ Beta } & \multirow[b]{2}{*}{$\mathrm{T}$} & \multirow[b]{2}{*}{ Sig } \\
\hline & B & Std. Error & & & \\
\hline Constant & 1600.57 & 314.23 & - & 5.09 & 0.000 \\
\hline $\begin{array}{l}\text { Perceived } \\
\text { susceptibility }\end{array}$ & -170.95 & 10.20 & -0.12 & -1.75 & 0.08 \\
\hline $\begin{array}{l}\text { Perceived } \\
\text { severity }\end{array}$ & -9.44 & 10.33 & -0.06 & -0.91 & 0.36 \\
\hline $\begin{array}{l}\text { Perceived } \\
\text { benefits }\end{array}$ & 7.82 & 15.48 & 0.03 & 0.5 & 0.61 \\
\hline $\begin{array}{l}\text { Perceived } \\
\text { barriers }\end{array}$ & 1600.57 & 11.16 & -0.14 & 5.09 & 0.000 \\
\hline
\end{tabular}

dents' employment, marital status, parents' employment, their education, and students' income level ( $P>0.05)$. The multivariate regression produced perceived barriers as the most single strong determinant of calcium intake (beta $=-0.14, \mathrm{P}=0.04)$. The results are given in Table 3 .

Osteoporosis or reduced bone density has hit people in all populations globally (Heidarnia, 2003). The most important method to induce a behaviour change is developing an understanding of people's behaviour and determinant factors of their behaviour (Anastasia et al., 2014). The present study aims to find these factors. We discuss the findings in following five sections.

\section{University students' calcium intake}

The daily level is $945 \mathrm{mg} /$ day, below the daily recommended level of 1000-1300 mg/day for young and adolescent people. Khadem Haghighian (2012) and Ghaffari et al. (2010) reported 810 and $620 \mathrm{mg} /$ day, respectively, of calcium intake for female and male university students (Ghaffari et al., 2010), which are also below the recommended standard level. Anastasia et al. (2014) reported in their interventional study that pre-inter- vention level of calcium intake was $650 \mathrm{mg} /$ day, and post-intervention level was improved to $1400 \mathrm{mg} /$ day of calcium intake (Shojaeezadeh, 2011). They designated a descriptor of 'very unsatisfactory' for $650 \mathrm{mg} /$ day of intake; an 'unsatisfactory' descriptor for 650-1300 mg/ day of calcium intake; and a 'satisfactory' descriptor for above $1300 \mathrm{mg} /$ day of calcium intake. They found that 36.9 per cent of students were in 'very unsatisfactory' level; 40.1 per cent were in 'unsatisfactory' level; and only 23 per cent of students were classified as 'satisfactory.'

Shojaezadeh et al. (2011) noted in their study that only 16 per cent of the females had satisfactory level of calcium intake, with other 78 per cent in unsatisfactory level (Ebadi et al., 2012). Ebadifard Azar et al. (2012) reported that only 14 per cent of females consumed dairy products in acceptable levels (Khorsandi et al., 2013). The most frequently consumed item is common yogurt (with average of $222 \mathrm{mg} /$ day of calcium), and in the second place is low-fat milk with calcium intake of $126 \mathrm{mg} /$ day. The least frequently consumed items are milk-produced tasty fat. Given the low intake 
of calcium among university female students and other female groups, an understanding of the causes of such low intakes is necessary to prevent osteoporosis. Thus, we recommend that the health authorities consider this issue in their strategies of health promotion and education to improve the level of calcium intake among the young and adolescent population.

\section{Perceived susceptibility}

Perceived susceptibility describes the extent to which individuals assess themselves susceptible to a disease and or they think they would suffer the disease (Glanz et al., 2008). The present study found a moderate level of perceived susceptibility among female students about osteoporosis with 15.91 out of 30. Khorsandi et al. (2013) reported a similar level (53.2 out of 100) for perceived susceptibility (Shojaezadeh et al., 2012). However, Ghaffari et al. (2010), Shojaezadeh et al. (2011), and Ellen et al. (2010) reported a score well below the average for perceived susceptibility (Ghaffari et al., 2010; Ellen et al., 2012; Khorsandi et al., 2010). Some other studies reported a satisfactory score for the construct (Khorsandi et al., 2013); different methods of data collection, environment, and different target groups could contribute to diversity and disparity of the scores. We found a negative significant relationship between calcium intake and perceived susceptibility. Given the role of this construct in improving nutritional behaviour, it is recommended that interventions based on health education models (HBM and other models) be made in a group of young and adolescents.

\section{Perceived severity}

Perceived severity denotes the extent to which the individuals understand the severity of a disease and whether they think that the disease may bring death, disability and pain for them (Glanz et al., 2008). We reported an above-average level of the construct for female students with 18.19 out of 30 , well in line with results found in Ebadifard Azar et al. and Shojaezadeh et al. (Khorsandi et al., 2013; Ellen et al., 2012). Ellen et al. (2012) reported a similar score (17.34 out of 30) for the construct (Khorsandi et al., 2010). We found also a positive and significant relationship between calcium intake and perceived susceptibility and severity. We recommend interventions to improve the scores of perceived susceptibility and severity about the disease.

\section{Perceived benefits}

This construct denotes to what extent the individuals evaluates the benefits of a preventive behaviour and they thus seek beneficial behaviour (Glanz et al., 2008). Students in our study received score of 13.79 out of 30 which was not in acceptable levels. Other stud- ies reported scores well above the average (Ghaffarfi et al., 2010; Khorsandi et al., 2010). Differences in scores could be accounted for by the different target groups and research environment. We found no significant relationship between students' daily calcium intake levels and perceived benefits. We recommend interventions to improve this construct among students.

\section{Perceived barriers}

Perceived barriers denotes the negative and potentially harmful aspect of a health behaviour, which could act as barriers in the way of a healthy behavoir (Glanz et al., 2008). Costs, being received and loved, abandoning other behaviours and students' attitudes to type of foods are examined in finding score of this construct. The present study reported an above average score of 13.49 out of 30 , which denoted that students have an average and thus satisfactory understanding of barriers on calcium intake, well in line with other research (Ghaffari et al., 2010, Ebadi Fard et al., 2012; Khorsandi et al., 2010). This study found a negative and significant relationship between perceived barriers and calcium intake. Multivariate regression analysis showed the perceived barriers as the strongest determinant of calcium intake. The study recommends further research to improve perceived barriers.

\section{Demographic variables and calcium intake}

There was a significant relationship between parents' education; students reporting their mothers' education as high school diploma, received the highest levels of calcium. No further significance was found between other demographic variables and calcium intake. Other studies found similar trend (Ghaffari et al., 2010; Ellen et al., 2012). Given the role of the family, further research is necessary to investigate parents' education and its role in healthy behaviour.

\section{CONCLUSION}

The present research enjoyed some advantages, mainly, a homogenous group of subjects (female university students), a single theoretical framework, and data collection method. The study found that the level of 945.63 $\mathrm{mg} /$ day of calcium intake was not satisfactory. Students are low in their perceived susceptibility and severity of osteoporosis and very low in their perceived benefits; however, they showed an average understanding of barriers of calcium intake. We also found a significant relationship between calcium intake and perceived susceptibility, severity, barriers and female parents' education, but no significance between other variables was detected. The study suggests perceived barriers as the strongest determinant of calcium intake. Further studies 
with holistic approach and with inclusion of other variables are recommended to examine calcium intake and WHO's six strategies of osteoporosis and measurement of bone density.

\section{ACKNOWLEDGEMENTS}

The authors would like to thank all the Department of Health officials and female students in Shahid Beheshti University of Medical Sciences who helped in conducting this research.

\section{REFERENCES}

Anastasia MS, Troy BA, KORBA C, Tucker L (2014). Stages of change algorithm for calcium intake by male college students. J Am Diet Assoc; 106:904-907.

Bonura F. (2015). Prevention, screening, and management of osteoporosis: an overview of the current strategies. Postgrad Med 2015 Jul; 121(4): 5-17.6. Anderson JJB. Nutrition and bone health. In: Mahan LK, Escott-Stump S. Krause's Food, Nutrition and Diet Therapy. $12^{\text {th }}$ ed. Philadelphia: W.B. Saunders; 2014. P. 614-635.

Ebadi Fard Azar F, Solhi M, Zohoor AR, Ali Hosseini M. (2012). The effect of health belief model on promoting preventive behaviors of osteoporosis among rural women of Malayer. The journal of Qazvin University of medical sciences (JQUMS); 16(2): 58-64.[In Persian]

Ellen E, Lori WT, Stuart LU. (2012). Osteoporosis knowledge, beliefs, and calcium intake of college students: utilization of the health belief model. Open Journal of Preventive Medicine; 2(1): 27-34.

Ghaffari M, Tavassoli E, Esmaillzadeh A, Hasanzadeh A. (2010). The effect of education based on health belief model on the improvement of osteoporosis preventive nutritional behaviors of second grade middle school girls in Isfahan. Journal of Health system research; 6(4): 714-723. [In Persian]

Glanz KA, Rimer BA, Viswanth K. (2008). Health behavior and health education theory, research and practice. $4^{\text {th }}$ ed. San Farancisco: Josey- Bass publisher; 8-30

Heidarnia E. (2003). Discussions in the process of health education. Tehran, Zamani Naser publishing; 92-109.

Keramat A, Larijani B, Adibi H, Hossin nejad A, Choopra A, Patoarthan B, (2012). Risk factors of osteoporosis among menopause women in urban area, Danesh o tandorosti; 2(3). [In Persian]. Available at: http://www.sid.ir/fa/VEWSSID/J_ pdf/46113860306.pdf

Khadem Haghighian H, Vahid F, Hekmatdost A, Arefhosseini R. (2015). Relationships between dietary calcium intake and body mass index and waist circumference in male students residing in dormitories of Tabriz University of Medical Sciences in 2009. Journal of Health (Ardabil); 3(2): 59-66. [In Persian]

Khorsandi M, Shamsi M, Jahani F. (2010). The effect of education based on health belief model on the improvement of osteoporosis preventive behaviors in pregnant women of Arak city. Daneshvar Journal; 18(89): 1-10. [In Persian]

Khorsandi M, Shamsi M, Jahani F. (2013). The survey of practice about prevention of osteoporosis based on health belief model in pregnant women in Arak city. J Rafsanjan Univ Med Scie; 12(1): 35-46. [In Persian]

Lesan sh, Mirheidari Z, Sotoode G, Khajenasiri F, Kohdani F. (2010). Cross-sectional study of nutritional habits and behaviors of women teachers related to osteoporosis. Hayat $(3,4) 16$ : 86-94. [In Persian]

Ministry of health and medical education: disease prevention and control office (2016). Guide to diagnosis, prevention and treatment of osteoporosis. Tehran: Pub Centered prevention disease. [In Persian]

Mudest N, Tamayoz T. (2012). Glossary of terms and concepts of health education and promotion. Tranlated by; Shams M, Karimi Shahanjirini A. $1^{\text {th }}$ ed, Tehran, Tandis Publications, 2012.

National Institutes of Health (2016), Office of Dietary Supplements, Calcium Dietary Supplement Fact Sheet. Available at: http://ods.od.nih.gov/factsheets/Calcium-HealthProfessional/ \#h2

Shojaeezadeh D, Mehrab Beik A, Mahmoodi M, Salehi L. (2011). The effect of education on knowledge, attitude and practice of women clients Imam Khomeini Aid Committee about preventing osteoporosis using the health belief model. Iranian Journal of Epidemiology; 7(2): 30-37. [In Persian]

Shojaezadeh D, Sadeghi R, Tarrahi M J, Asadi M, Lashgarara B. (2012). Application of health belief model in prevention of osteoporosis in volunteers of Khorramabad city health centers, Iran. Journal of health system research; 8(2): 183-192. [In Persian]

The International Osteoporosis Foundation (IOF) (2008). Facts and statistics about osteoporosis and its impact. Available at: http://www. iofbonehealth. org/facts-and- statistics. (Accessed 2010 June 10).

The International Osteoporosis Foundation (IOF) (2013). What is osteoporosis? 2013. Available at: http://www.iofbonehealth. org/what-is-osteoporosis. (Accessed 2013 October 23).

Torshizi L, Anoosheh M, Ghofranipour F, Ahmadi F, Houshyar A. (2009). The effect of education based on health belief model on preventive factors of osteoporosis among postmenopausal women. Iran Journal of Nursing (IJN); 22(59):71-82. [In Persian]

World Health Organization (2016). Diet, nutrition and the prevention of chronic diseases. Available at:http://www.who.int/ dietphysicalactivity/publications/trs916/summary/en/

World Health Organization (2016). Diet, nutrition and the prevention of chronic diseases. Available at: http://www.who.int/ dietphysicalactivity/publications/trs916/en/gsfao_osteo.pdf

World Health Organization (WHO) (2016). Tobacco and osteoporosis: tobacco free initiative (TFI). Available at: http://www. who.int/tobacco/research/osteoporosis/en/. (Accessed 2013 October 20) 